\title{
AMENDMENTS
}

\section{Author Correction: Fecal microbiota transplantation for refractory immune checkpoint inhibitor-associated colitis}

Yinghong Wang (DD, Diana H. Wiesnoski, Beth A. Helmink, Vancheswaran Gopalakrishnan, Kati Choi, Hebert L. DuPont, Zhi-Dong Jiang, Hamzah Abu-Sbeih (D), Christopher A. Sanchez, Chia-Chi Chang, Edwin R. Parra, Alejandro Francisco-Cruz, Gottumukkala S. Raju, John R. Stroehlein, Matthew T. Campbell ID, Jianjun Gao, Sumit K. Subudhi ID, Dipen M. Maru, Jorge M. Blando, Alexander J. Lazar, James P. Allison, Padmanee Sharma, Michael T. Tetzlaff, Jennifer A. Wargo and Robert R. Jenq

Correction to: Nature Medicine https://doi.org/10.1038/s41591-018-0238-9, published online 12 November 2018.

In the version of this article originally published, an author was missing from the author list. Alexander J. Lazar should have been included between Jorge M. Blando and James P. Allison. The author has been added to the list, and the author contributions section has been updated to include Alexander J. Lazar's contribution to the study. The error has been corrected in the print, PDF and HTML versions of the manuscript.

Published online: 27 November 2018

https://doi.org/10.1038/s41591-018-0305-2

\section{Author Correction: A human monoclonal antibody prevents malaria infection by targeting a new site of vulnerability on the parasite}

Neville K Kisalu, Azza H Idris, Connor Weidle, Yevel Flores-Garcia, Barbara J Flynn, Brandon K Sack (D), Sean Murphy, Arne Schön, Ernesto Freire, Joseph R Francica, Alex B Miller, Jason Gregory, Sandra March, Hua-Xin Liao, Barton F Haynes, Kevin Wiehe, Ashley M Trama, Kevin O Saunders, Morgan A Gladden, Anthony Monroe, Mattia Bonsignori, Masaru Kanekiyo D, Adam K Wheatley, Adrian B McDermott, S Katie Farney, Gwo-Yu Chuang, Baoshan Zhang, Natasha Kc, Sumana Chakravarty, Peter D Kwong, Photini Sinnis, Sangeeta N Bhatia, Stefan H I Kappe, B Kim Lee Sim (D, Stephen L Hoffman, Fidel Zavala, Marie Pancera and Robert A Seder

Correction to: Nature Medicine https://doi.org/10.1038/nm.4512, published online 19 March 2018

In the version of this article originally published, data were incorrectly ascribed to monoclonal antibody CIS34 because of a labeling error. The data were generated with monoclonal antibody CIS04. The corrections are presented below.

Results:

Published text: "Four of the five monoclonal antibodies (CIS23, CIS34, CIS42 and CIS43) showed dose-dependent binding to rPfCSP and PfSPZ in an ELISA and had maximal effective concentrations $\left(\mathrm{EC}_{50} \mathrm{~s}\right)$ ranging $0.003-0.134 \mu \mathrm{g} / \mathrm{ml}$ and $0.017-0.08 \mu \mathrm{g} / \mathrm{ml}$, respectively (Fig. 1c)."

Correct text: "Four of the five monoclonal antibodies (CIS23, CIS04, CIS42 and CIS43) showed dose-dependent binding to rPfCSP and PfSPZ in an ELISA and had maximal effective concentrations $\left(\mathrm{EC}_{50} \mathrm{~s}\right)$ ranging $0.003-0.134 \mu \mathrm{g} / \mathrm{ml}$ and $0.017-0.08 \mu \mathrm{g} / \mathrm{ml}$, respectively (Fig. 1c)."

Published text: "Four of the PfCSP-specific monoclonal antibodies (CIS23, CIS34, CIS42 and CIS43) that were isolated from memory $\mathrm{B}$ cells, and three of the PfCSP-specific monoclonal antibodies (mAb04, mAb09 and mAb10) isolated from plasmablasts showed dosedependent inhibition of sporozoite invasion of hepatocytes (Supplementary Fig. 1b)."

Correct text: "Four of the PfCSP-specific monoclonal antibodies (CIS23, CIS04, CIS42 and CIS43) that were isolated from memory B cells, and three of the PfCSP-specific monoclonal antibodies (mAb04, mAb09 and mAb10) isolated from plasmablasts showed dosedependent inhibition of sporozoite invasion of hepatocytes (Supplementary Fig. 1b)."

Published text: "Passive transfer of the monoclonal antibody CIS43 in mice following intravenous infection led to the highest reduction $(\sim 2-4$ logs $)$ of the liver-stage parasite burden in a dose-dependent manner $(P<0.008$; Fig. 2a,b) as compared to the liver-stage parasite burden in untreated mice or those receiving transfection filtrate (mock); the second-highest reduction was observed following transfer of CIS34, which led to a $\sim 2-\log$ reduction $(P<0.008$; Fig. 2a)." 